\title{
EFFICIENCY INCREASE MODELS OF TWO-LEVEL ECHELON LOGISTIC SYSTEMS
}

\author{
Valery Lukinskiy ${ }^{1}$, Vladislav Lukinskiy ${ }^{2}$ \\ ${ }^{1,2}$ National Research University Higher School of Economics (HSE), \\ St. Petersburg, Russia \\ ${ }^{1}$ 007(812)644-59-11(+61517), lukinskiy@mail.ru \\ 2007(812)644-59-11(+61517),vladas27@mail.ru
}

\begin{abstract}
In this article we deal with the approach to logistic systems efficiency increase on the basis of various forms of logistic integration development in supply chains, with modified variants of model of economic order quantity for the echelon two-level systems which allow considering the costs correlations at the different system levels, the different stock warehousing strategies, the multi-nomenclature of orders. The appropriate calculations have been done for the suggested modified models approbation.
\end{abstract}

Keywords: logistics system, supply chain, economic order quantity model, inventory disposition

\section{Introduction}

The increase of supply chains (SC) management efficiency requires further theory and methodology development of this scientific direction, wherein, it is obvious that the most perspective solution of this problem is to work out and improve the logistic functions and operations integration at all levels of logistics systems (LS) management.

Logistic integration issues are the subject of the numerous researches which results are presented in the scientific literature. Specifically, the theoretical aspects of logistic integration have been examined in the works of Giannakis and Croom (2004), Kovách and Spens (2007). The prospects of logistic integration development are stated, for instance, in the works of Kent and Flint (1997), Larson et al. (2007), Lukinskiy et al. (2012). Analyzing the presented sources, it should be noted that the majority of scientists link the further logistic integration development to the development of inter-organizational mechanisms of SC components interaction including the logistic functions management.

Modern logistic systems and supply chains development requires new models designing that allow describing the similar systems and the occurring processes, as well as forming management mechanisms with the use of the logistic integration potential. Specifically, at the modern stage of logistic theory evolution, and also as a result of researches on the functioning practice of various branch belonging, it is expedient to consider the modern logistic systems as multilevel ones.

If we study the research results connected with the various functioning aspects of multilevel logistic systems it will allow us to distinguish the following directions:

- the research of environment factors, specifically, the demand characteristics and inflationary process impact on parameters of two-level inventory disposition system (for instance, research of Smith and Dekker (1997), Gumus and Guneri (2009), Guo and Li (2014);

- the algorithmization of multilevel systems management methods, including the use of wellknown logistic technologies (within a framework of DPR systems, the researches on supply schedule algorithm were made by Yoo et al. (1997), the supply parameter calculation according to the JIT technology is presented in work of Yang and Lin (2010), the issues of the algorithmic platform forming of the examined systems management are studied in the works of Caggiano et al. (2009);

- the development of methodology for the multilevel systems management based on the optimization models (Fahimnia et al., 2008; Pal et al., 2014; Lai et al., 2014).

At the same time, within the view point of a search of the efficient methods for the increase of competitiveness and economical subjects activity effectiveness, the most productive direction is one that is based on the logistic integration conditions.

The analysis of a number of sources (Ballou, 2004; Bowersox and Closs, 1996; Christopher, 2004; Stock and Lambert, 2001) has shown that despite the increasing volume of researches and obtained results, the following can be stated: 
Firstly, in most part of these researches the simple logistic links (SLL) with one warehouse are examined instead of the logistic chains including several interrelated warehouses for inventory storage at every level;

Secondly, analytical models mainly describe interfunctional integration of the logistic operations and functions;

Thirdly, costs reduction possibilities in supply chains using traditional methods (economic order quantity (EOQ) model, multi-nomenclature, multiple periods strategy and so on) in a certain sense have been exhausted.

The fundamentally new method of accounting the integral connections between elements is the model that proposed by S. Axsäter (2006). The example of the two-level system of linear configuration inventory disposition allowed obtaining the dependence for the economic order quantity determination that was called multi-echelon model EOQ. Calculation technique using the echelon models is analogical to the classic model of economic order quantity of Harries-Wilson (Harries, 1913). The objective function in these models is total costs connected with the purchasing and inventory holding. Desired variables are the volumes of the stock refill orders that lead to the objective function minimization. The main difference of the echelon models is that we examine not one but several inventory disposition levels.

The basic terms which define the possibility of echelon EOQ models usage are the following:

- determined finite need for the material resources (here we mean the need for ready-to-use products in production and/or distribution field);

- constant and evenly distributed in time consumption intensity of final consumers;

- constant time of order execution;

- fixed elements of stock costs.

However, the study of the two-level linear model of S. Axsäter (2006) has shown that it reflects only a part of possible variants of the integrable logistic operations and doesn't allow taking into consideration some situations related to:

- $\quad$ alternative inventory consumption variant at the supplier's warehouse (the top level);

- different variants to register the costs of the current inventory storage and others,

that defines the relevance of further development of the modified models complex that reflect the specification of given situations (Lukinskiy et al., 2017).

\section{The Analysis of Economic Order Quantity Model for the Echelon Two-Level Systems}

The main calculation formulas for the echelon model of economic order quantity (EOQ) were obtained considering the following conditions and limitations:

1. The product demand for the level «1» is determined, evenly distributed in time and has a constant intensity during the whole examined period;

2. The order $\left(C_{0 i}\right)$ and stock holding costs calculated on one product unit $\left(c_{h i}\right)$ are constant during the whole examined period of time;

3. «1» and «2» levels products are indivisible and the one unit of goods at level 1 corresponds to the one unit of goods at the level 2.

4. Between the order quantity for the system levels «1» and «2» there is the following relation:

$Q_{o 2}=k \cdot Q_{o 1}$

where: $k$ is a positive number (consignments multiple index);

$Q_{o i}$ is an economic order quantity at the $i$-th level of system.

5. In the system the instantaneous order supply possibility is assumed: in case of order supplying from the system link at the level 1 at the rate of $Q_{o l}$, the part of the stock at the level 2 at the rate of $Q_{o l}$ can be shipped to the client at the level 1 (Fig.1). Thus, the mean stock at the level 2 during the cycle will be:

$\bar{Q}_{2}=\frac{(k-1) \cdot Q_{1}}{2}$

It can be seen from Figure 1 that the demand at the level 2 has a discrete nature which is determined by the supply coordination at the levels 1 and 2 .

Total costs in the system (Fig.1) will be: 
$C_{\Sigma}=C_{\mathrm{or} 1}+C_{\mathrm{h} 1}+C_{\mathrm{or} 2}+C_{\mathrm{h} 2}=\frac{C_{01} \cdot A}{Q_{1}}+\frac{Q_{1} \cdot c_{h 1}}{2}+\frac{C_{02} \cdot A}{k \cdot Q_{1}}+\frac{Q_{1} \cdot(k-1) \cdot c_{h 2}}{2}$.

Total costs function for the two-level linear configuration system (formula 3 ) is a convex function for two variables $-Q_{1}$ and $k$. Therefore to find the $Q_{1}$ value we can use a standard method: to take the first derivative from the expression (3) on $Q_{1}$, equate it to the zero and express the desired parameter.

As a result we will obtain the value for the economic order quantity calculation at the level 1:

$Q_{o p t 1}=\sqrt{\frac{2 \cdot A \cdot\left(C_{01}+\frac{C_{02}}{k}\right)}{c_{h 1}+c_{h 2} \cdot(k-1)}}$.

Stock at the level 2

Stock at the level 1

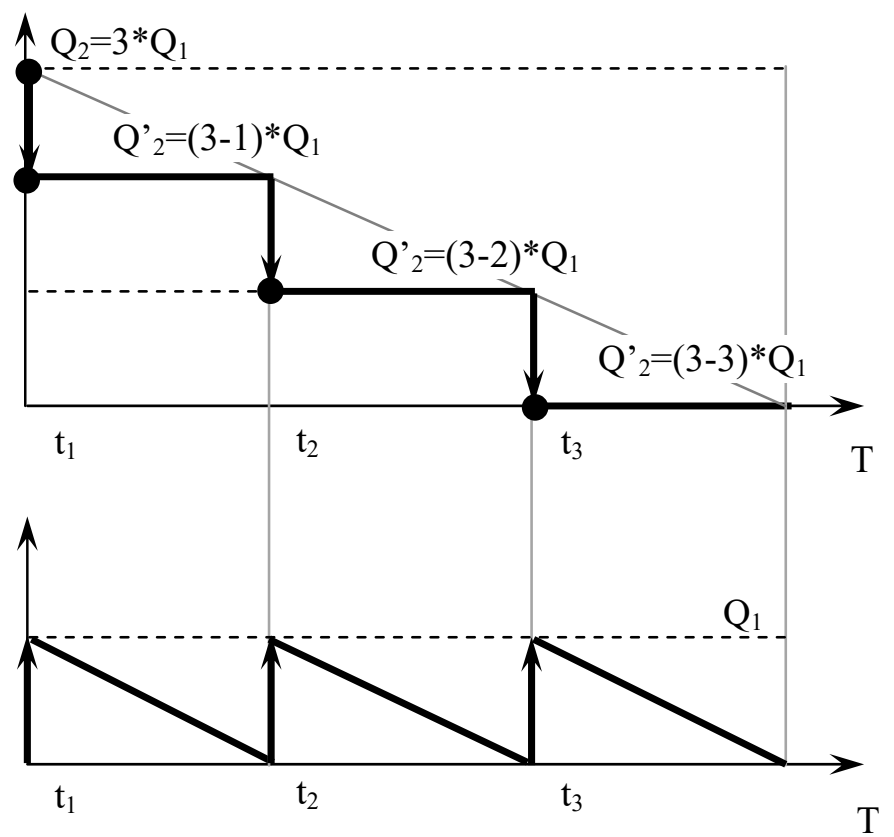

Figure 1. Products stocks relation at the levels 1 and 2 at $\mathrm{k}=3$

Inserting the value (4) into the total costs formula (3) instead of $Q_{1}$, we will get the value for the total minimum costs calculation:

$$
C_{\Sigma \min }=\sqrt{2 \cdot A \cdot\left(C_{01}+\frac{C_{02}}{k}\right) \cdot\left(c_{h 1}+c_{h 2} \cdot(k-1)\right)} .
$$

To find $k$ coefficient in Axsäter's (2006) work the following approach is used: the derivative $d\left(C_{\Sigma \min }\right)^{2} / d k$ is taken which later is equated to the zero. After some necessary transformations we have:

$k=\sqrt{\frac{C_{02} \cdot\left(c_{h 1}-c_{h 2}\right)}{C_{01} \cdot c_{h 2}}}$.

The economic order quantity at the level 2 is calculated with the formula (1), where we insert $k$ and $Q_{\text {optl }}$ values gained by formulas (4) and (6).

At the same time, the Axsäter's (2006) approach implementation has a restriction related to the correctness of its implementation in case of $c_{\mathrm{h} 1}<c_{\mathrm{h} 2}$, i.e. holding costs at the level 2 (central warehouse) 
always have to be lower than holding costs at the level 1 (regional warehouses). This statement is based on the fact that holding costs are traditionally defined as a percent of product value, and product value at the regional warehouses increases by the additional costs of the transportation and cargo processing:

$c_{\mathrm{h} 1}=\left(C_{\mathrm{p}}+\Delta C\right) \cdot f>c_{\mathrm{h} 2}=C_{\mathrm{p}} \cdot f$,

where: $C_{p}$ is a product price;

$\Delta C$ is an added value;

$f$ is a percent of a product price per holding costs.

However, the inequality (7) is not always just; various level of warehouse technical equipment at the different levels of logistic systems, distinctions in systems of tariff calculations for the warehousing services and other factors can lead to the following situations:

a) $c_{h 2} \geq c_{h 1}$, then according to the formula (6) coefficient $k$ becomes a complex number;

b) $c_{h 2}=c_{h 1}$, in this case coefficient $k$ equals zero so that $Q_{\mathrm{o} 2}$ dependence makes no sense;

c) $k \leq 1$ (stocks at the second level are not held, warehouse cargo processing is done with the help of cross-docking technology).

Since this type of a problem has no analytical solution, let us study the possibilities of numerical method for finding the minimal costs and inventory indexes. For the numerical problem solution it is necessary to record the total costs equation (3). The economic supply consignment quantity $Q_{1}$ at the different $k$ coefficient values is calculated with the formula (4). Knowing the economic consignment quantity, we can calculate the minimal total costs.

Let us figure on appropriate calculations using supply chain with the following basic data:

- annual need for the production (A) is 40000 un.;

- supply organization costs for the first level link $\left(\mathrm{C}_{01}\right)$ are 500 c.u., for the second level link $\left(\mathrm{C}_{02}\right)-700$ c.u.;

- holding costs of the product unit for the first level link $\left(c_{\mathrm{h} 1}\right)$ equal 3 c.u., for the second level $\operatorname{link}\left(\mathrm{c}_{\mathrm{h} 2}\right)-9$ c.u.

The diagram showing the way total costs depend on the supply consignments quantity for the different $k$ is shown in the Figure 2.

The analysis of the given numerical solution on the Figure 2 allows us to conclude that there forms the value range of supply consignments for the different $k$ coefficient values which make total costs values close to the minimal where $k \geq 2$. It should be noted that the more is difference between holding costs and order costs at both levels the more distinct the total costs values for the various $k$ are.

\section{Modified Variants of the Economic Order Quantity Model for the Echelon Two-Level Systems}

Inventory indexes calculation models in the two-level systems allow us to show different types of interactions between the levels and are the analytical basis for the defining of the rational cooperation type using total logistic costs criteria. At the same time, these models adaptation for their subsequent usage to describe the real processes occurring in supply chains requires their further specification and forming the modified variants complex that allows considering the following processes features:

- correlation variants of holding costs at the different system levels (model 1);

- various strategies of inventory warehousing (model 2);

- order multi-nomenclature (model 3).

It is obvious that presented variants do not fully reflect processes specifications in modern supply chains; however, we believe that their description problem in the modified models demands the quickest solution because it allows formalizing most decisions which are made in the inventory disposition twolevel system.

Model 1 which takes into consideration the correlation variants of holding costs at the different system levels.

To overcome the typical limitations of presented in section 2 model, we suggest introducing an additional condition: in case of order receipt from the system link at the level 1 in the quantity of $Q_{\mathrm{o} 1}$ the part of the stocks at the level 2 in the quantity of $Q_{\mathrm{o} 1}$ is not shipped to the client at the level 1 immediately, but it has to be held during the first cycle. Thus, to define the order volume multiplicity we use the multiplier $(k+1)$. The distinction between two examined models is shown graphically in the Figure 3. 


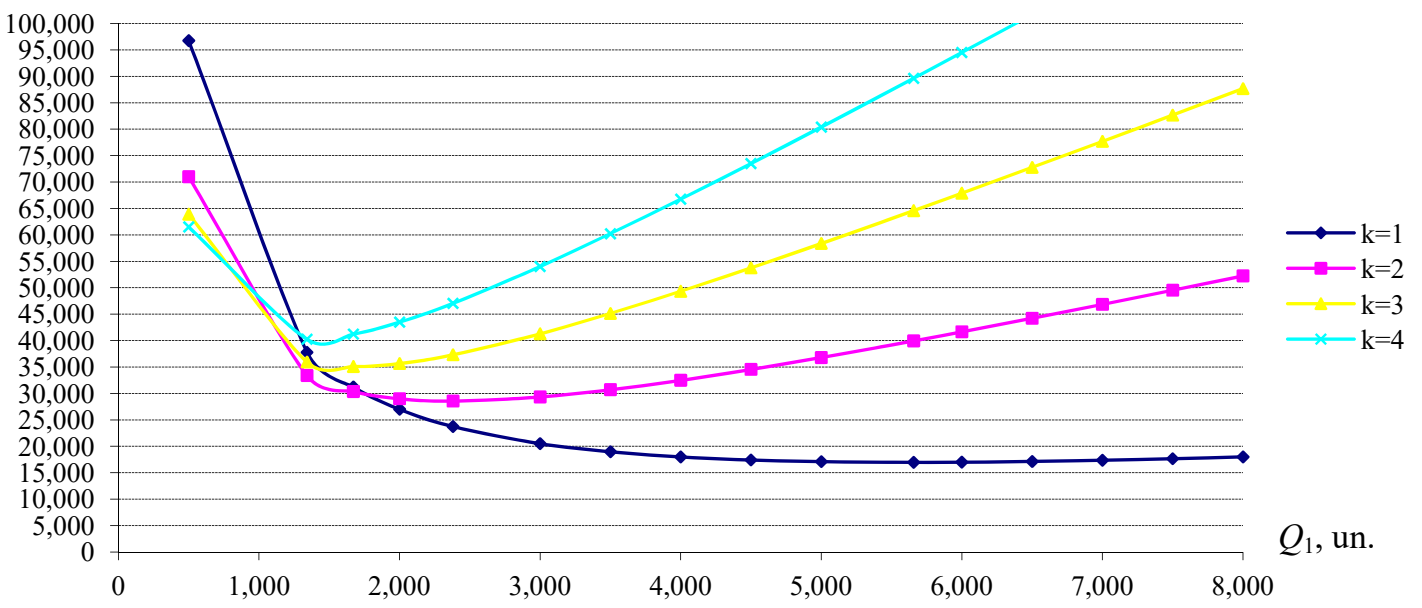

Figure 2. Total costs dependences on the order consignment volume $Q_{1}$ and k (for $C_{\mathrm{h} 1}<C_{\mathrm{h} 2}$ )

Model 2, which takes into account the inventory warehousing strategies. In all models known to the authors the holding costs are regarded as a part of production price held at the warehouse. Then, holding costs calculation depends on the average supply consignment quantity. Though, in forming the modified models, one has to consider other inventory warehousing strategies which are widely-spread in modern enterprise functioning practice, specifically, a warehouse space rent. In this case it is necessary to take into account the warehouse space (or volume) required for the whole supply consignment disposition when we calculate the holding costs (Lukinskiy et al., 2012).

Thereby, holding costs for the first level link are calculated by the formula:

$C_{\mathrm{h} 1}=\alpha_{1} \beta_{1} Q_{1}$

where $\alpha_{1}$ is holding costs of the production unit at the first system level in view of occupied space (or volume) of warehouse, c.u. $/ \mathrm{m}^{2}$ (or c.u. $/ \mathrm{m}^{3}$ ); $\left(\mathrm{m}^{3} / \mathrm{un}.\right)$

$\beta_{1}$ is a coefficient which considers the spatial size of product unit at the first system level, $\mathrm{m}^{2} / \mathrm{un}$.

Model a

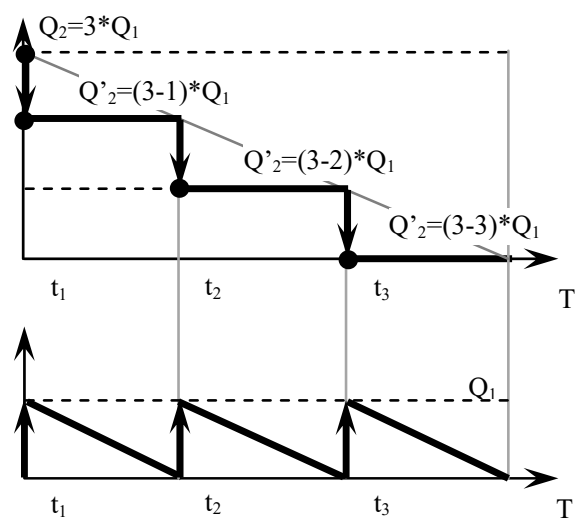

Model $b$

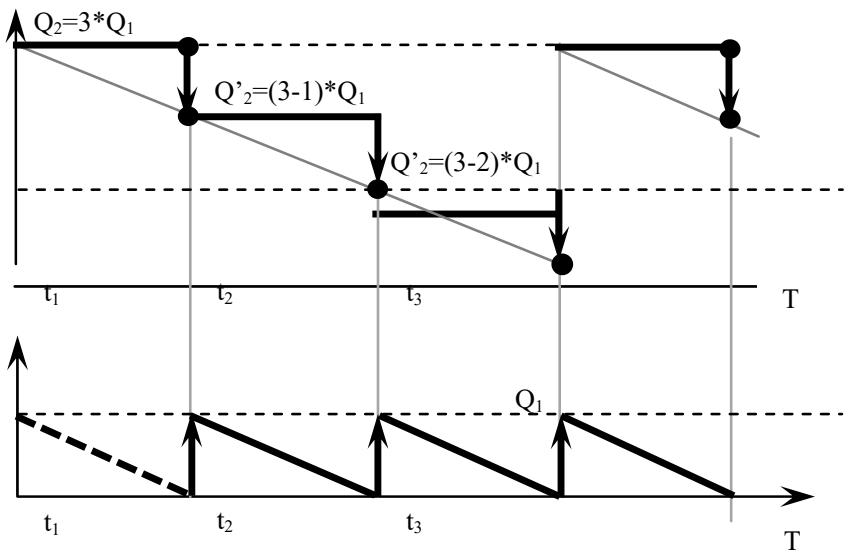

Figure 3. Alternative approaches to the description of the inventory consumption: a - Axsäter's model (2006); b - modified model (model 1)

Then total costs in the two-level system will equal:

$C_{\Sigma}=\frac{C_{01} A}{Q_{1}}+\alpha_{1} \beta_{1} Q_{1}+\frac{C_{02} A}{k Q_{1}}+\alpha_{2} \beta_{2} k Q_{1}$.

Optimal parameters calculation formulae are presented in Table 1. 
Table 1. Parameters of modified integrated models

\begin{tabular}{|l|c|c|}
\hline \multirow{2}{*}{ Parameter } & \multicolumn{2}{|c|}{ Calculation formulae for the modified variants } \\
\cline { 2 - 4 } \multicolumn{1}{c|}{1} & model 1 & model 2 (for the warehouse space rent) \\
\hline $\begin{array}{l}\text { Economic order } \\
\text { quantity at the } \\
\text { level «1» }\end{array}$ & $Q_{o p t 1}=\sqrt{\frac{2 \cdot A \cdot\left(C_{01}+\frac{C_{02}}{k}\right)}{c_{h 1}+c_{h 2} \cdot(k+1)}}$ & $Q_{o p t 1}=\sqrt{\frac{A \cdot\left(C_{01}+\frac{C_{02}}{k}\right)}{\alpha_{1} \beta_{1}+\alpha_{2} \beta_{2}}}$ \\
\hline $\begin{array}{l}\text { Economic order } \\
\text { quantity at the } \\
\text { level «2» }\end{array}$ & $Q_{o 2}=k \cdot Q_{o 1}$ & $Q_{o 2}=k \cdot Q_{o 1}$ \\
\hline $\begin{array}{l}\text { Multiplicity } \\
\text { parameter of } \\
\text { consignments }\end{array}$ & $k=\sqrt{\frac{C_{02} \cdot\left(c_{h 1}+c_{h 2}\right)}{C_{01} \cdot c_{h 2}}}$ & $k=\sqrt{\frac{C_{02} \cdot \alpha_{1} \beta_{1}}{C_{01} \cdot \alpha_{2} \beta_{2}}}$ \\
\hline $\begin{array}{l}\text { Total minimal } \\
\text { costs in the } \\
\text { system }\end{array}$ & $C_{\Sigma \min }=\sqrt{2 \cdot A \cdot\left(C_{01}+\frac{C_{02}}{k}\right) \cdot\left(c_{h 1}+c_{h 2} \cdot(k+1)\right)}$ & $C_{\Sigma \min }=2 \sqrt{A \cdot\left(C_{01}+\frac{C_{02}}{k}\right) \cdot\left(\alpha_{1} \beta_{1}+\alpha_{2} \beta_{2} k\right)}$ \\
\hline
\end{tabular}

It has to be noted that for this inventory warehousing strategy in the supply chains (warehouse space rent) the limitation related to the necessity of $C_{\mathrm{h} 2}<C_{\mathrm{h} 1}$ maintenance is insignificant when we define the $k$ coefficient optimal parameter.

Model 3, considering order multi-nomenclature. The shown above models and their modified variants apply to one-good supply. Meantime, inventory structure analysis results in current supply chains show that in the multi-level systems the supplies of a nomenclature positions large quantity are carried out; besides, if for the similar systems we try to use the models developed for the one-nomenclature supply, it leads to the examined systems parameters distortion and does not allow optimizing total logistic costs quantity. Besides, the supply level dynamics at the different levels is coordinated for every nomenclature position individually, consequently, the supply periodicity substantially differs for different goods. It is obvious that such a situation is related to the inefficient use of resources in a supply chain; it is possible to remove arising negative effects with the use of unified optimal periodicity of supply for $n$ nomenclatures.

Thereby, it is urgent to form two-level linear supply chains models reflecting the multinomenclature of supplies carried out in them.

Let us examine a two-level linear system where $n$-nomenclature position supplies are carried out.

Total costs in the examined two-level system will be calculated by formula:

$C_{\Sigma}=C_{\sum 1}+C_{\sum 2}=\frac{\mathrm{D}}{T}\left(\sum_{i=0}^{n} C_{1 i}+\frac{\sum_{i=0}^{n} C_{2 i}}{k}\right)+\frac{T}{2 \mathrm{D}}\left(\sum_{i=1}^{n} A_{i} c_{\mathrm{h} 1 i}+(k-1) \sum_{i=1}^{n} A_{i} c_{\mathrm{h} 2 i}\right) \rightarrow \min$,

where $A_{i}$ is a supply volume of $i$-th nomenclature for the calculation period at the first and second levels;

$T$ - a time of simultaneous n-nomenclatures supply;

$\mathrm{D}$ - a calculation period, for example, a year;

$C_{10}$ - costs connected with the 1 level link supply organization;

$C_{1 i}$ - costs connected with the $i$-th product preparation at the multi-nomenclature supply forming;

$c_{\mathrm{h} 1 i}$ - holding costs of the $i$-th product unit during the calculation period $\mathrm{D}$;

$k$ - a consignment multiplicity coefficient (sought positive integer), $k=1,2, \ldots m$;

$C_{2 i}$ - costs of the organization of the $i$-th type product supply at the second level warehouses;

$C_{20}$ - costs related to the 2 level link supply organization;

$C_{\mathrm{h} 2 i}$ - holding costs of the $i$-th type of product unit during the calculation period.

The main calculation formulae for the model parameters can be presented in Table 2 . 
Table 2. Parameters of the integrated EOQ model for the two-level inventory disposition in view of the order multi-nomenclature

\begin{tabular}{|c|c|}
\hline Parameter & Calculation formulae \\
\hline $\begin{array}{l}\text { Economic order quantity at the } \\
\text { level «1» }\end{array}$ & $Q_{01 i}=A_{i} \sqrt{\frac{2 \cdot\left(\sum_{i=0}^{n} C_{1 i}+\left(\frac{\sum_{i=0}^{n} C_{2 i}}{k}\right)\right)}{\sum_{i=1}^{n} A_{i} C_{h 1 i}+(k-1) \sum_{i=1}^{n} A_{i} C_{h 2 i}}}$ \\
\hline $\begin{array}{l}\text { Economic order quantity at the } \\
\text { level «2» }\end{array}$ & $Q_{02 i}=k \cdot Q_{02 i}$ \\
\hline $\begin{array}{l}\text { Parameter of consignments } \\
\text { multiplicity }\end{array}$ & $k=\sqrt{\frac{\sum_{i=0}^{n} C_{2 i} \cdot\left(\sum_{i=1}^{n} A_{i} C_{h 1 i}-\sum_{i=1}^{n} A_{i} C_{h 2 i}\right)}{\sum_{i=0}^{n} C_{1 i} \cdot \sum_{i=1}^{n} A_{i} C_{h 2 i}}}$ \\
\hline Total minimal costs in the system & $C_{\Sigma \min }=\sqrt{2 \cdot\left(\sum_{i=0}^{n} C_{1 i}+\left(\frac{\sum_{i=0}^{n} C_{2 i}}{k}\right)\right) \cdot\left(\sum_{i=1}^{n} A_{i} C_{h 1 i}+(k-1) \sum_{i=1}^{n} A_{i} C_{h 2 i}\right)}$ \\
\hline
\end{tabular}

\section{Economic Order Quantity Model Approbation for the Echelon Two-Level Systems}

The initial data about the four product types are presented in Table 3.

Table 3. Initial data for the model parameter calculation of the two-level echelon supply chain at the multi-nomenclature supply

\begin{tabular}{|c|c|c|c|c|c|c|c|c|c|}
\hline Product type & $A_{i}$, un. & $\begin{array}{l}C_{10} \\
\text { c.u. }\end{array}$ & $C_{1 i}$, c.u. & $\begin{array}{c}C_{10}+C_{1 i} \\
\text { c.u. }\end{array}$ & $\begin{array}{l}C_{h 1 i,} \\
\text { c.u. }\end{array}$ & $\begin{array}{l}C_{20} \\
\text { c.u. }\end{array}$ & $\begin{array}{l}C_{2 i}, \\
\text { c.u. }\end{array}$ & $\begin{array}{c}C_{20}+C_{2 i} \\
\text { c.u. }\end{array}$ & $C_{h 2 i}$, c.u. \\
\hline 1 & 3000 & \multirow{4}{*}{18} & 6 & 24 & 2.5 & \multirow{4}{*}{40} & 9 & 49 & 1.0 \\
\hline 2 & 2000 & & 4 & 22 & 2.0 & & 7 & 47 & 0.8 \\
\hline 3 & 1000 & & 4 & 22 & 1.5 & & 6 & 46 & 0.3 \\
\hline 4 & 500 & & 6 & 24 & 1.5 & & 10 & 50 & 0.3 \\
\hline
\end{tabular}

The results of developed models implementation are presented in Table 4. There are the results of the echelon two-level supply chains for six variants.

Having analysed the Table 4, we can conclude the following:

- depending on the chosen variant of calculation there is considerable variation of parameters for each logistic system link: minimal total costs correspond to the fourth variant of calculation; maximal ones - to the fifth variant;

- the best variant is the united variant of the integrated supply chain (mean value of minimum costs for the fourth and sixth variants is $\mathrm{C}_{\Gamma}=1860 \mathrm{c.u}$.).

The obtained results are informative and can be used as an analytical basis while choosing the configuration of the inventory disposition systems. 
Table 4. Calculation results of the total costs for the various variants of the two-level echelon supply chain at the multinomenclature supply

\begin{tabular}{|c|c|c|c|c|c|c|c|}
\hline \multirow{3}{*}{$\mathbf{N}$} & \multirow{3}{*}{ Model } & \multirow{3}{*}{$\begin{array}{c}\text { Calculation } \\
\text { variants quantity }\end{array}$} & \multirow{2}{*}{\multicolumn{4}{|c|}{$\begin{array}{c}\text { The multiplicity coefficient } k \\
\text { Product type }\end{array}$}} & \multirow{3}{*}{$\begin{array}{l}\text { Total costs, } \\
\text { c.u. }\end{array}$} \\
\hline & & & & & & & \\
\hline & & & 1 & 2 & 3 & 4 & \\
\hline 1 & $\begin{array}{l}\text { EOQ model: independent supply of each } \\
\text { nomenclature }\end{array}$ & 8 & \multicolumn{4}{|c|}{ Not calculated } & 2685 \\
\hline 2 & Multi-nomenclature supply for each level & 2 & \multicolumn{4}{|c|}{ Not calculated } & 1874 \\
\hline 3 & $\begin{array}{l}\text { Axsäter's model: two-level system for each } \\
\text { nomenclature }\end{array}$ & 4 & 2 & 2 & 3 & 3 & 2411 \\
\hline 4 & $\begin{array}{l}\text { Axsäter's model: two-level system for all } \\
\text { nomenclatures }\end{array}$ & 1 & \multicolumn{4}{|c|}{$\frac{1}{2}$} & 1668 \\
\hline 5 & $\begin{array}{l}\text { Modified model: two-level system for each } \\
\text { nomenclature }\end{array}$ & 4 & 3 & 3 & 4 & 4 & 2917 \\
\hline 6 & $\begin{array}{c}\text { Modified model: two-level system for all } \\
\text { nomenclatures }\end{array}$ & 1 & \multicolumn{4}{|c|}{3} & 2051 \\
\hline
\end{tabular}

\section{Further Researches}

In view of the fact that in the sources accessible to the authors there are almost no specific calculations of the inventory quantity in integrated logistic SC, we believe that it is urgent to pursue further researches and to summarise the results of corresponding inventory management theory sections.

One of the further research directions has to be the supply chains which are a distribution system, and the most spread of them are two-level ones with central supplier at the second level and certain companies number at the first level. Problem difficulty is caused by the variability of interaction types between the levels at the examined two-level systems. Reciprocally, this determines the variety of inventory management models that can be divided into three basic sub-groups: the first one - with independent processes, the second one - with the use of co-ordination and the third one - integration models.

One more direction of researches suggests the transition to the three-level systems, for example, a central warehouse (production) - a distributive centre (regional warehouse) - a consumer (trade subdivision).

\section{References}

1. Axsäter, S. (2006) Inventory control. 2nd Edition. International Series in Operations Research \& Management Science. Springer Science \& Business Media.

2. Ballou, R.H. (2004) Business Logistics: Supply Chain Management. New Jersey: Pearson Education, Inc.

3. Bowersox, D.J., Closs, D.J. (1996) Logistical Management. The Integrated Supply Chain Process. New York: McGraw-Hill Companies, Inc.

4. Caggiano, K.E., Jackson, P.L., Muskstadt, J.A., Rappold, J.A. (2009) Efficient computation of timebased customer service levels in a multi-item, multiechelon supply chain: A practical approach for inventory optimization. European Journal of Operational Research, Vol. 199, no.3, pp. 744-749.

5. Christopher, M. (2004) Logistics and Supply Chain Management. Strategies for Reducing Cost and Improving Service. 2nd Edition. New Jersey: Prentice Hal, Inc.

6. Fahimnia, B., Luong, L., Marian, R. (2008) An integrated model for the optimization of a twoechelon supply network. Journal of Achievements in Materials and Manufacturing Engineering. Vol. 31, issue 2, Desember, 477-484.

7. Giannakis, M., Croom, S.R. (2004) Toward the Development of a Supply Chain Management Paradigm: A Conceptual Framework. The Journal of Supply Chain Management. Spring. P.27-37.

8. Gumus, A.T., Guneri, A.F. (2009) A multi-echelon inventory management framework for stochastic and fuzzy supply chains. Expert Systems with Applications, Vol. 36, no. 3, pp.5565-5575.

9. Guo, C., Li, X.P. (2014) A multi-echelon inventory system with supplier selection and order allocation under stochastic demand. International Journal of Production Economics, Vol. 151, pp.37-47.

10. Harris, F. (1913) How many parts to make at once. The Magazine of Management. Vol.10 (2), P. 135-136, 152. (Operation Research Society of America. 1990). 
11. Kent, J.L. (Jr.), Flint, D.J. (1997) Perspectives on the evolution of logistics thought. Journal of Business Logistics. Vol.18, No.2. P.15-29.

12. Kovách, G., Spens, K.M. (2007) Logistics Theory Building. ICFAI Journal of Supply Chain Management, Vol.IV, No.4, pp.7-27.

13. Lai, X., Chen, Z., Giri, B., Chiu, C.-H. (2014) Two-Echelon Inventory Optimization for Imperfect Production System under Quality Competition Environment. Mathematical Problems in Engineerung. Hindawi Publishing Corporation. Vol. 2015, Article ID 326919, 11 pages. http://dx.doi.org \10.1155\2015\326919.

14. Larson, P.D., Poist, R.S., Halldórsson, Á. (2007) Perspectives on Logistics vs. SCM: A Survey of SCM Professionals. Journal of Business Logistics. Vol.28, No.1, pp.1-24.

15. Lukinskiy, V.S., Lukinskiy, V.V., Malevich, J.V., Plastuniak, I.A., Pletneva, N.G. (2012) Models and methods of the logistics theory. St.Petersburg: SPbSUEE. $404 \mathrm{p}$.

16. Lukinskiy, V.S., Lukinskiy, V.V., Shulzhenko, T.G. (2017) Logistic systems efficiency increase based on the supply chains integration. In: Procedia Engineering 178. Proceedings of the $16^{\text {th }}$ International Conference "Reliability and Statistics in Transportation and Communication" (RelStat'16), 19-22 October 2016, Riga, Latvia, pp. 117-122. DOI: 10.1016/j.proeng.2017.01.073

17. Pal, B., Sana, S.S., Chaudhuri, K. (2014) Optimal Pricing and Ordering Policy for Two Echelon Varying Production Inventory System. Journal of Industrial Engineering. Hindawi Publishing Corporation. Vol. 2014, Article ID 429836, 11 pages. - http://dx.doi.org $\backslash 10.1155 \backslash 2014 \backslash 429836$

18. Smith, M.A., Dekker, R. (1997) On the (S-1, S) Stock Model for Renewal Demand Processes. Probability in the Engineering and Informational Sciences, 11, pp.375-386.

19. Stock, J.R., Lambert, D.M. (2001) Strategic Logistics Management. 4th ed. Boston: McGraw-Hill Irwin.

20. Yang, M.F., Lin, Y. (2010) Applying the linear particle swarm optimization to a serial multi-echelon inventory model. Expert Systems with Applications, Vol. 37, no. 3, pp.2599-2608.

21. Yoo, Y.J., Kim, W.S., Rhee, J.T. (1997) Efficient inventory management in multi-echelon distribution systems. Computers \& Industrial Engineering, Vol. 33, no. 3, pp.729-732. 